\title{
The Theoretical Orientation and Path Choice of Enterprise Culture Construction from the Perspective of Cultural Consciousness
}

\author{
$\mathrm{He} \mathrm{LV}$ \\ Humanistic and Social Science Department \\ Jilin Institute of Chemical Technology \\ Jilin City, China
}

\author{
Sheng Chang \\ School of Pharmacy \\ Jilin Medical University \\ Jilin, China
}

\begin{abstract}
The enterprises cultural construction should be based on a new vision so as to fulfill the historical mission of establishing a powerful cultural nation. This projects the importance of cultural consciousness. By theoretically orienting enterprise culture construction based on cultural consciousness, this paper concludes the mechanism of cultural consciousness in the enterprise culture construction. Then, the ways to realize cultural construction are obtained. They include the understanding Chinese traditional culture, focusing on the principle role of enterprise members and constructing the comprehensive development strategy self-consciously. On this basis, the relevant theory and orientation are presented in this research.
\end{abstract}

Keywords-cultural consciousness; enterprise culture construction; theoretical orientation; path choice

\section{INTRODUCTION}

Under the guidance of the historical mission for establishing a powerful cultural nation at present, the importance of cultural consciousness is becoming more obvious. As the important carriers and practioners of economy operation, enterprises are considered as the creators of social productive forces. Therefore, enterprises need to undertake the historical mission to establish a powerful cultural country in the new age. Meanwhile, enterprise culture serves as key part and growing point of social culture. It is the base for supporting the sustainable development of enterprises, and also a platform for enterprises to construct a powerful cultural country. Therefore, to complete the historical mission and form cultural endowment which is beneficial for the development of enterprises, it is necessary to analyze the theoretical orientation and path choice of enterprise culture construction based on cultural consciousness. In addition, this can make enterprises objectively understand their cultures so that they can reasonably put the mission into practice.

\section{THE THEORETICAL ORIENTATION OF ENTERPRISE Culture CONSTRUCTION BASED ON CULTURAL CONSCIOUSNESS}

\section{A. Cultural Consciousness}

Culture is the accumulation of conducts, moral norms and customs of mankind in the progress of transforming nature and social development. It reflects the prominent differences among different groups in terms of values, thinking modes and spiritual pursuits. Culture can be classified into three parts: material culture, institutional culture and spiritual culture. Material culture which varies with time is the most active part in culture; characterized by authority, institutional culture determines the characteristics of all kinds of cultures; , spiritual culture is the most conservative part in all kinds of cultures and has nationality. While culture has been fundamentally changed in modern society from two aspects: on the one hand, the power of culture resulted from the changes of social structure and living style is produced with the development of history; on the other hand, when people encounter the problem concerning dominant culture mode, they self-consciously obtain the strength of culture. As these two cultural statuses alternatively occur, the cultural connotation of the history of human society becomes more predominant and therefore cultural consciousness has been more unprecedentedly important.

Fei Xiaotong, the scholar who proposed the concept of cultural consciousness, considered that the concept can reflect important meanings from small clue. It can reveal problems of China through the investigation into the nations with little population. Its significance lies in that people have self-knowledge for their culture. That is, people understand the origin and formation as well as the characteristics and development tendency of their culture. Self-knowledge aims to strength the independence ability of cultural transformation so that the independent position for adapting to new environment and selecting culture in the new era can be obtained. [1]

Cultural consciousness is a kind of conscious status based on the scientific understanding of the importance, 
development law and historical responsibility of culture. It refers to that subjects should have the cultural status and historical mission by self-examination and consciousness so as to realize the survival and development of a nation or themselves. Cultural consciousness is shown to be reasonable. With the advance of science, technology and economy, human's capability for reasonably managing their living status and spiritual worlds, gradually increases. In the wake of abundant cultural productivities, human's cultural consciousness has been developed into a higher stage. In addition, cultural consciousness is historical: we can investigate the historical connotation of cultural consciousness from its statuses in different stages. Meanwhile, the connotation of cultural consciousness in different historical stages can be obtained from the historical evolution. Furthermore, cultural consciousness is practical: practice means the self-consciously initiative activities of human and only in practices can human know the difference between human and animals. Accordingly, only in practice can culture and cultural consciousness as well as the influence of cultural consciousness on the development of human society be realized. Moreover, the cultural choice in the process of cultural consciousness can merely happen in practice.

\section{B. Enterprise Culture}

Cultural phenomena are supposed to be understood by introducing them in human history in relevant studies. The cultural connotations can be investigated clearly from the perspective of social and historical development. For instance, the development of material production and economic activities is not merely the accumulation of material wealth, but presents as the innovation and development of productive relations and productivity. While the innovation and development is mainly presented as culture progress. For example, the problems arising from the fields including economy, politics, technology and management, etc., are essentially cultural problems. In the process of social and historical development, a variety of complex cultural phenomena therefore are found. Enterprise culture is no exception.

Enterprise culture refers to the sum of values, thinking modes and spiritual pursuits which are identified and consciously abided by enterprise members in the long-time management practice. Through enterprise culture, different characteristics between two enterprises can be known. In general, enterprise culture is characterized by objective existence, unique particularity, relative stability, dynamic permeability, practice, etc. In the early stage of reform and opening-up, enterprise culture was introduced into China as a foreign culture. At that time, the enterprises in China mainland were just broken away from the planned economy and served as independent subjects to participate in the market competition. Owing to the richness of cultural connotation and the difference of cultural studies in different modes and perspectives, culture has not been generally defined. To date, the concept of enterprise culture has not yet been consistent. Generally speaking, all material and spiritual achievements of enterprises can be classified into enterprise culture. Enterprise culture includes the following elements: goal, values, spirits, institution, morality, environment and image, of enterprises. Meanwhile, enterprise culture is a complete cultural system composed of three layers: firstly, material culture refers to the technologies and environment of enterprises; the second one is institutional culture which reflects the economic attribute of enterprises; thirdly, conceptual culture, also called as spiritual culture, is the core of enterprise culture.

\section{Mechanism of Cultural Consciousness}

Enterprise culture construction denotes the intentional and planned activities and processes by enterprises to cultivate enterprise culture with special characteristics.2 Enterprise culture is an objective existence in all enterprises. However, owing to of self-consciously constructing enterprise culture is based on the fully understanding of enterprise culture, thus, not all enterprises have enterprise culture construction.

Firstly, cultural consciousness serves as the cohesive function of enterprise culture. The cohesive function of enterprise culture plays a decisive role in providing spiritual basis for enterprises, solving internal conflicts and increasing the attraction of enterprises to members. In addition, the cohesive function is a prominent one with various functions of enterprise culture. To give full play of the cohesive function, perceptive senses of identity belonging by enterprise members are supposed to be created through designing, popularizing and developing enterprise culture. The creation of these senses relies on the internalization influence of enterprise culture on the enterprise members. Because enterprise members are the subjects of enterprises, the behaviors of enterprises have to be implemented by enterprise members. That is, this internalization process is realized by the cultural consciousness of enterprise members. As philosophical anthropologist M. Landman once said, "Without culture, human is nothing". [3]

Next, cultural consciousness is required in the formation of the development law of enterprise culture. The development law of enterprise culture is to obtain the fundamental motivation for developing enterprise culture. To promote the construction of enterprise culture, this power is supposed to be applied. However, to give full play of the enterprise culture, it inevitably connects, conflicts and competes with other cultures, thus forming the fundamental power for developing enterprise culture. The application of the development law in enterprise culture based on cultural consciousness means that the enterprise members' subjective initiative should correspond to this objective fact in the construction of enterprise culture. The conflict and competition in the culture construction are objective, absolute and cannot be artificially eliminated. While cultural fusion opposites to the conflict and competition of enterprise culture, and determines the possibility and tendency of the development of enterprise culture. Thus in this process, the development law of enterprise culture plays its roles. Meanwhile, enterprise culture in this process is generally invisible and only concrete cultural frictions or conflicts 
occur. Rather than creating culture at one's pleasure, enterprise culture requires to be constructed by objectively using the development law of culture and cultural consciousness from the aspect of actual economic operation. In the meantime, the enterprise culture is constructed based on the main conflict.

Finally, cultural consciousness is needed for the selfinnovation of enterprise culture. With the further understanding of enterprise culture by enterprise members, the content of enterprise culture changes with the change of the historical positions of enterprises. Accordingly, the degree of cultural consciousness improves. The selfinnovation of enterprise culture means the changes of the whole or part of the enterprise culture caused by the variations of the elements of enterprise culture: the changes of material culture results in that institutional culture which arises from the changes of conceptual culture. Since the conceptual culture is the key of the enterprise culture, the changes of conceptual culture plays a leading role in the selfinnovation of enterprise culture. In the accumulation and inheritance of enterprise culture, enterprise culture construction from the perspective of cultural consciousness generally dissatisfies the current situations. It always tries to abandon and acquire something to realize self-innovation to finally achieve an ideal state. In this process, the enterprise culture without self-innovation cannot be accumulated and inherited. Therefore, they cannot be further developed, let alone supporting enterprise development. Meanwhile, the enterprise culture with self-innovation improves the members' understanding to their culture in the management practice. This makes that self-consciously constructing enterprise culture agree with history and reality. As a result, enterprise culture construction can be improved in a spiral form.

\section{THE PATH ChOICE OF ENTERPRISE CUlturE CONSTRUCTION BASED ON CULTURAL CONSCIOUSNESS}

As to the path choice of enterprise culture construction from the perspective of cultural consciousness, comprehensive analysis is conducted by combing the specialty of enterprise culture construction and introducing the choice of enterprise culture into the path choice of cultural consciousness.

\section{A. Conscious Understanding of Chinese Traditional Culture}

Though enterprise culture was introduced from the western countries, it has to be integrated with Chinese traditional culture with Chinese characteristics. Otherwise, it cannot promote the development of Chinese enterprises and the foreign enterprises in China.

There is no cultural form which can be inherited without the nutrition of the traditional culture. This is because the traditional culture containing thinking principles, values and folk customs is presented with inheritance and the basis of active new culture. Chinese traditional culture has long-timer honored, for example, the culture ideas include just and dignity, a world for all, self-strengthening, showing mercy to others, don't do unto others what you don't want others do unto you, vigorous and promising, and harmony and peace, etc. From these values, we can learn national philosophical wisdom and experience the cultural essences of enterprise culture. For instance, the perception of Chinese to history, observation of reality, pursuit of spiritual world and selfdiscipline of behaviors can be known. Deng Xiaoping said that "we should know Chinese history as it is the spiritual power for the development of China." 4 Xi Jinping also pointed out that "we should build cultural confidence and the sense of national pride by establishing the pride of long history of Chinese civilization"; "Chinese traditional culture can provide beneficial inspirations for the governance of China and moral construction."

Therefore, the conscious understanding of Chinese traditional culture is helpful to construct enterprise culture from the perspective of culture consciousness. On the one hand, traditional culture is related with enterprise culture which is served as realistic culture in the construction of enterprise culture. On this basis, the essences of traditional culture can be absorbed into enterprise culture and therefore used in the enterprise management. For instance, Confucian culture can be employed to reconstruct the spiritual culture of entrepreneurs. In addition, the Mahayana thought of Buddhism can be applied to provide inspirations for cultivating the social responsibility of enterprises. Besides, the thought of Zen Buddhism can be utilized to investigate innovative enterprise culture. On the other hand, as advance and backwardness occur simultaneously, the traditional culture can be used by discarding dross and select essence, eliminating the false and retaining the true, and comprehensive consideration." This means that the outdated, negative and conservative parts in the traditional culture needs to be eliminated with the aims of taking the modern construction of enterprise culture as standard.

After the conscious understanding of Chinese traditional culture, the constructed enterprise culture has been developed into a part of current Chinese culture, thus realizing the self-innovation of enterprise culture.

\section{B. S elf-consciously Focusing on the Role of Enterprise Members}

The subjects of enterprise culture construction are the enterprise members consisting of leaders and employees. To construct enterprise culture from the perspective of cultural consciousness, the roles of enterprise members needs to be concentrated self-consciously. This is because culture acts by real men; while enterprise culture is presented by its influence on enterprise members and is transmitted through the interactions of members. Chairman Mao Zedong once pointed out in the Yan'an Forum on Literature and Art that "there already exist many forms of literary arts in people' $\mathrm{s}$ life. Even though in natural forms, they are rough but most active and essential. From this aspect, they outshine than any forms of literary art and are the only inexhaustible resource of all forms of literary arts." 5 Therefore, self-consciously focusing on the functions of enterprise members can realize the enterprise culture construction from the perspective of cultural consciousness. 
On the one hand, the role of enterprise leaders should be emphasized in the conscious construction of enterprise culture. As the demonstrators, enterprise leaders should design and conclude enterprise culture. They are supposed to take the long-term development of enterprises as their main goal and appeal enterprise employees to gain the senses of identity and belonging of enterprise culture so as to maintain enterprise cohesion. Meanwhile, they are the executors with firm values of enterprise culture and encourage employees to imitate. As a result, employees can self-consciously develop and innovate enterprise culture.

On the other hand, emphasis is expected to be laid to roles of employees in the conscious construction of enterprise culture. As the most active factors of productivity in enterprise activities, enterprise employees are the direct creators of material and spiritual wealth for enterprises. Their production practices are the main sources of enterprise culture, such as the Iron Man Spirit of Daqing Oilfield, in Daqing, China. In general, enterprise employees are not only the subjects to promote and participate in the enterprise culture construction, but also the objects to accept the enterprise culture and be transformed in the construction process. In the meantime, when the cultural status of employees is not consistent with the requirements of enterprise culture, enterprise culture can only be possibly inherited and innovated by self-conscious adjustment of employees.

\section{Self-consciously Constructing the Comprehensive Development Strategy for Enterprises}

It is necessary to for enterprises to formulate development strategies in the construction of enterprise culture. Therefore, the requirement for constructing development strategy of enterprises based on cultural consciousness should be made. Firstly, under fierce market competition, the development strategy of enterprises has to be formulated according to the enterprise culture so as to obtain sustainable success. That is to say, enterprise culture guides the choice of the development strategy. The concrete formulation process is as follows: with the development of enterprises, new development strategies are prone to occur in the relocation and adjustment of enterprise culture. These strategies are managed under the guidance of enterprise culture. The enterprise culture construction is also the process of acquiring new development strategies; next, the development strategy of enterprises is implemented based on enterprise culture. To achieve the strategic goal of enterprise, formulating development goal should be firstly made; while how to precisely implement this goal is the key. This is owing to the formulation, reconstruction or internal adjustment of all significant strategies need to be transformed into the enterprise culture including enterprise spirit, values and code of conduct. As enterprise culture conflicts with the development strategy, the enterprise culture as the spiritual source is rarely changed; while the development strategies of enterprises are therefore always transformed. Then, to formulate development strategies, the predication, analysis and evaluation of strategic process and strategic environment are necessary for long-term perspective cultural consciousness of enterprises. Finally, enterprise culture can act on economic operation of enterprises by the infiltration of material, institutional and conceptual cultures to all aspects of enterprises' economic activities. Thereinto, the multiple-dimensional relationships between the enterprise culture and enterprises' economic activities can be clearly presented, thus generating spiritual power and cultural motivation of enterprise culture on the enterprises' economic activities. In the formulation of the development strategies for enterprises, comprehensive strategies involving from all aspects of enterprises should be included. Such formulation is fulfilled in the conscious construction of enterprise culture: self-consciously constructing comprehensive development strategies. Therefore, the selection of the ways to construct enterprise culture has to be investigated based on the strategy of enterprise culture management: enterprise culture needs to be constructed from the macro concern.

\section{CONCLUSION AND IMPLICATIONS}

Only constructing enterprise culture from perspective of cultural consciousness, enterprise culture can be formed into a scientific system with confident and self-strengthening culture. This paper studies the enterprise culture construction from the perspective of cultural consciousness. The corresponding path choice in the enterprise culture construction is the theory and orientation proposed in this research. Therefore, this paper can provide a reference for constructing enterprise culture based on cultural consciousness. It is helpful to enhance the theoretical and practical innovation of enterprise culture construction from the perspective of cultural consciousness.

\section{REFERENCES}

[1] http://www.chinawriter.com.cn/2007/2007-03-19/23306.html

[2] Shui Nen W, The enterprise culture theory and practice., University of Peking Press. Beijing: 2014, pp.159-160.

[3] MichaelLandmann , Jiayan. Philosophical Anthropology [ M]. Guzhou People's Publishing, Guiyang: 1988, pp.159-160.

[4] Xiao ping Deng,Selected Works Of Deng Xiaoping, vol. III, People's Publishing House, 1993, pp. 358.

[5] Selected Works of Mao Tse-tung,vol. III, People's Publishing House, 1992, pp.860. 